University of Texas at El Paso

ScholarWorks@UTEP

\title{
Why West-to-East Jetlag Is More Severe: A Simple Qualitative Explanation
}

Olga Kosheleva

The University of Texas at El Paso, olgak@utep.edu

Vladik Kreinovich

The University of Texas at El Paso, vladik@utep.edu

Follow this and additional works at: https://scholarworks.utep.edu/cs_techrep

Part of the Other Social and Behavioral Sciences Commons

Comments:

Technical Report: UTEP-CS-17-62

Published in Journal of Innovative Technology and Education, 2017, Vol. 4, No. 1, pp. 113-116.

\section{Recommended Citation}

Kosheleva, Olga and Kreinovich, Vladik, "Why West-to-East Jetlag Is More Severe: A Simple Qualitative Explanation" (2017). Departmental Technical Reports (CS). 1162.

https://scholarworks.utep.edu/cs_techrep/1162

This Article is brought to you for free and open access by the Computer Science at ScholarWorks@UTEP. It has been accepted for inclusion in Departmental Technical Reports (CS) by an authorized administrator of ScholarWorks@UTEP.For more information, please contact Iweber@utep.edu. 


\title{
Why West-to-East Jetlag Is More Severe: A Simple Qualitative Explanation
}

\author{
Olga Kosheleva and Vladik Kreinovich \\ University of Texas at El Paso \\ $500 \mathrm{~W}$. University \\ El Paso, TX 79968, USA \\ olgak@utep.edu,vladik@utep.edu
}

\begin{abstract}
Empirical data shows that the jetlag when traveling west-to-east feels more severe than the jetlag when traveling east-to-west. At present, the only explanation of this empirical phenomenon is based on a complex dynamical systems model. In this paper, we provide a simple alternative explanation. This explanation also explains - on the qualitative level the empirical data on relative severity of different jetlags.
\end{abstract}

\section{When Is the Jetlag More Severe: Empirical Facts and Their Current Explanation}

When is the jetlag more severe: empirical data. It is known that when we travel west-to-east, a jetlag feels more severe that after a similar east-to-west travel.

A more specific data is given in [1]. In this paper, as a measure of severity of a jetlag, the authors selected the number of days that a body needs to fully adjust to the new time zone. The authors compared the recovery times for traveling 3,9 , and 12 time zones eastward and westward. These times are given in the following table:

\begin{tabular}{|c||c|c|}
\hline time shift & $\begin{array}{c}\text { recovery time } \\
\text { west-east }\end{array}$ & $\begin{array}{c}\text { recovery time } \\
\text { east-west }\end{array}$ \\
\hline \hline 3 hours & $4_{+}$days & $3_{-}$days \\
\hline 9 hours & 14 days & 8 days \\
\hline 12 hours & 10 days & 10 days \\
\hline
\end{tabular}

Here, $4_{+}$means a little more than 4 days, and $3_{-}$similarly means a little less than 3 days. 
How this is currently explained. A current explanation for this empirical phenomenon is based on the complex analysis based on dynamical systems [1].

What we do in this paper. In this paper, we provide a simple explanation for the jetlag difference. Not only we explain why west-to-east jetlag is more severe, we also explain - on the qualitative level - why some jetlags in the above table feel more severe than others.

\section{Our Explanation}

Let us consider a typical person. To compare the effects of east-to-west and west-to-east travel, let us consider a typical person living at some location A. This person wakes up around $7 \mathrm{am}$, works from 8 am to $12 \mathrm{pm}$ and from $1 \mathrm{pm}$ to $5 \mathrm{pm}$, and goes to sleep around $11 \mathrm{pm}$.

Let us first explain why this person is more affected by the west-to-east jetlag than by the east-to-west one.

What happens when this person goes east. Suppose that this typical person goes east, to a new location $\mathrm{E}$ which is 4 time zones further east, and tries to keep the same schedule in the new location.

- When the person tried to wake up at 7 am new E-time, it is still 3 am A-time and thus, in the beginning, still 3 am according to this person's biological time. So, this person is still sleepy.

- When the person goes to work from 8 am to 5 pm local (E-)time, then, according to his/her biological time, it is between 4 am and $1 \mathrm{pm}$. So, during almost half of this time, the person's biological clock is still set at sleep: not the best time to be productive.

- Finally, when it is time to go to sleep, it is $11 \mathrm{pm}$ E-time, but only $7 \mathrm{pm}$ biological time. So, the person is not sleepy at all, and has hard time going to sleep.

What happens when this person travels west. Suppose now that the next trip of this person is west, to a new location $\mathrm{W}$ which is 4 time zones further west, and also tries to keep the same schedule at the new location.

- When the person tries to wake up at 7 am local (W-)time, it is $11 \mathrm{am}$ on his/her biological clock, so he/she is ready to wake up.

- When the person goes to work from 8 am to $5 \mathrm{pm} \mathrm{W}$-time, then, according to his/her biological time, it is between $12 \mathrm{pm}$ and $9 \mathrm{pm}$. This is a usual awake time, so the person has no problem staying awake and working productively.

- Finally, when it is time to go to sleep, it is $11 \mathrm{pm}$ W-time, and 3 am biological time - so the person is very sleepy, and has no problem going to sleep. 
Conclusion: we have a simple explanation of why west-to-east travel is more severe. We have seen that on all the stages of daily activities, a person traveling west suffers more than a person traveling east. This explains why west-to-east jetlag is more severe.

Comment. The above comparison does not means that a person traveling eastto-west does not feel any discomfort. Yes, the person traveling west, due to the difference in clocks, has a problem staying asleep W-early in the morning (when everyone is asleep), and staying awake at $7 \mathrm{pm} \mathrm{W}$-time, where everyone is still active. However, these problems do not affect this person's workday and many people living normal life wake up early and go to bed early anyway - this is even considered healthy.

Let us now compare different jetlags. As a measure of severity of a jetlag, let us take the number of hours when the working period (8-12 pm and 1-5 pm) in the local time falls under biological sleep time. We will place these times in a table similar to the first one.

In each cell of this table, the top line is the working period as it feels to the traveling person, and the bottom line is the number of hours (out of 8 ) when this person feels sleepy (because $11 \mathrm{pm}$ to $7 \mathrm{am}$ is his/her normal sleep time):

\begin{tabular}{|c||c|c|}
\hline time shift & $\begin{array}{c}\text { recovery time } \\
\text { west-east }\end{array}$ & $\begin{array}{c}\text { recovery time } \\
\text { east-west }\end{array}$ \\
\hline \hline 3 hours & $5-9$ am, $10-1 \mathrm{pm}$ & $11-3$ pm, $4-8 \mathrm{pm}$ \\
& 2 hours & 0 hours \\
\hline 9 hours & $\begin{array}{c}11-3 \text { am, } 4-8 \text { am } \\
7 \text { hours }\end{array}$ & $\begin{array}{c}5-9 \text { pm, } 10-2 \text { am } \\
3 \text { hours }\end{array}$ \\
\hline 12 hours & $\begin{array}{c}8-12 \text { am, } 1-5 \text { am } \\
5 \text { hours }\end{array}$ & $\begin{array}{c}8-12 \text { am, } 1-5 \text { am } \\
5 \text { hours }\end{array}$ \\
\hline
\end{tabular}

Comparing the sleepy times, we can sort all six cases into the following order (here, E3 means traveling east with a time shift of 3 hours, and $<$ means less severe):

$$
\mathrm{W} 3<\mathrm{E} 3<\mathrm{W} 9<\mathrm{E} 12=\mathrm{W} 12<\mathrm{E} 9 .
$$

Interestingly, the same order of severity comes from the first table, when we compare the number of days needed to recover.

Thus, our simple explanation explains not only why the west-east travel feel more severe than the east-west one, it also explains which delays are more severe and which are less severe.

\section{Acknowledgments}

This work was supported in part by the National Science Foundation grant HRD-1242122 (Cyber-ShARE Center of Excellence). 


\section{References}

[1] Z. Lu, K. Klein-Cardeña, S. Lee, T. M. Antonsen, M. Girvan, and E. Ott, "Resynchronization of circadian oscillators and the east-west asymmetry of jet-lag", Chaos, 2016, Vol. 26, Paper 094811. 